\title{
HUBUNGAN ANTARA TINGKAT PENGHASILAN ORANG-TUA DENGAN RELASI PERTEMANAN SISWA DI SMP NEGERI 01 KELAS VIII ARGAMAKMUR
}

\author{
Larha Harnanda, Hadiwinarto, Rita Sinthia \\ Prodi Bimbingan dan Konseling Fakultas Keguruan dan Ilmu Pendidikan \\ Universitas Bengkulu \\ larhaharnanda07@gmail.com, hadiwin@unib.ac.id, ritasinthia@unib.ac.id
}

\begin{abstract}
ABSTRAK
Penelitian ini bertujuan untuk mengetahui hubungan antara tingkat penghasilan orang-tua dengan relasi pertemanan siswa kelas VIII SMP Negeri 01 Argamakmur. Sampel penelitian ini berjumlah 76 orang siswa yang diambil dengan teknik random sampling dari seluruh kelas VIII. Penelitian ini adalah penelitian deskriptif kuantitatif dengan teknik korelasi. Instrumen yang digunakan dalam penelitian ini adalah berupa kuesioner. Data dianalisis dengan menggunakan korelasi Chi Kwadrad. Hasil penelitian menunjukkan adanya hubungan positif yang signifikan antara tingkat penghasilan orang-tua dengan relasi pertemanan siswa dengan $\chi^{2}$ sebesar 21,490 dan nilai signifikan sebesar 0,006 ( $\left.<<0,05\right)$. Hal ini menujukkan bahwa terdapat hubungan positif antara tingkat penghasilan orang-tua dengan relasi pertemanan siswa, artinya siswa yang memiliki orang-tua dengan tingkat penghasilan tinggi dapat menjalin relasi pertemanan yang tinggi terhadap teman sebaya, dan siswa yang memiliki orang-tua dengan tingkat penghasilan rendah menjalin relasi pertemanan yang rendah dengan teman sebayanya.
\end{abstract}

Kata kunci: tingkat penghasilan orang tua, pertemanan siswa

\section{CORRELATION BETWEEN THE RATE OF PARENTS INCOME IN STUDENTS RELATIONSHIP OF JUNIOR HIGH SCHOOL STUDENTS CLASS VIII IN ARGAMAKMUR}

\begin{abstract}
The research aimed to know the correlation between the rate of parents income in students relationship of junior high school students class VIII in Argamakmur. The sample of this research was 76 students and the sample was taken by counducting random sampling technique. This research was a kind of descriptive quatitative in which the technique was correlation. The instruments that was used in this research were questionare. The data were analyzed by using correlation between the rate of parents income in students relationship in which was $\chi^{2}=21,490$ and the significant levelat of $0,006(p<0,05)$. This reveled that there was positive correlation between the rate of parents income in students relationship. It meant, the students whose parents having high income could have high chance in making close relationship with peers and the studets whose parents having low income could have low chance in making close relationship with peers.
\end{abstract}

Keywords: the rate of parents income, students relationship 


\section{Pendahuluan}

Pendidikan menjadi hal yang penting untuk menambah wawasan terhadap hal yang selalu berkaitan dengan kehidupan sehari-hari. Pengertian pendidikan bukan hanya untuk diketahui belaka melainkan dengan memahaminya lalu berusaha untuk menjalankan prosesnya berdasarkan apa yang memang tertuang dalam pengertian pendidikan tersebut. Seperti yang tertera dalam Undang-Undang No. 20 tahun 2003 Pasal 1 Ayat 1 bahwa yang dimaksud dengan pendidikan adalah usaha sadar dan terencana untuk mewujudkan suasana belajar dan proses pembelajaran agar peserta didik secara aktif mengembangkan potensi dirinya untuk memiliki kekuatan spiritual keagamaan, pengendalian diri, kepribadian, kecerdasan, akhlak mulia, serta keterampilan yang diperlukan dirinya, masyarakat, bangsa dan negara. Pendidikan nasional berfungsi mengembangkan kemampuan dan membentuk watak serta peradaban bangsa yang bermartabat.

Perkembangan siswa SMP termasuk dalam masa remaja. Menurut Hurlock (1980: 206) remaja berasal dari kata adolescence yang berasal dari bahasa latin adolescere yang artinya tumbuh menjadi dewasa atau tumbuh ke arah kematangan. Kata adolescence didefinisikan sebagai suatu periode pertumbuhan antara masa anak dan masa dewasa, periode atau tahapan intermediate antara masa anak dan masa dewasa.

Pada masa remaja, remaja lebih berorientasi kepada teman sebayanya. Teman sebaya merupakan aspek yang terpenting dalam relasi pertemanan remaja. Beberapa remaja akan melakukan apapun, agar dapat dimasukkan sebagai anggota kelompok teman sebaya. Menurut Santrock (2007:55) kawan-kawan sebaya adalah anak-anak atau remaja yang memiliki usia atau tingkat kematangan yang kurang lebih sama. Sedangkan Horrock dan Benimoff (dalam Hurlock, 1980:214) menjelaskan bahwa kelompok sebaya terdiri dari anggota-anggota tertentudari temantemannya yang dapat menerimanya dan kepada dirinyasendiri bergantung.

Masa remaja masih banyak siswa yang memiliki nilai berbeda dan lebih matang, hal ini tercermin dalam beralihnya penekanan pada minat yang berbeda. Menurut Hurlock (1980: 223), minat yang pada awal remaja dianggap sangat penting diantaranya minat sosial. Minat yang bersifat sosial bergantung pada kesempatan yang diperoleh remaja untuk mengembangkan minat tersebut dan pada kepopulerannya dalam kelompok. Seorang 
remaja yang status sosial ekonomi keluarganya rendah mempunyai sedikit kesempatan untuk mengembangkan minat sosialnya. Begitu pula dengan remaja yang status sosial keluarganya rendah cenderung akan mempunyai minat sosial terbatas. Adapun minat lain pada remaja yaitu minat pada simbol status. Simbol status merupakan simbol prestise, menunjukkan bahwa orang yang memilikinya lebih tinggi atau mempunyai status yang lebih tinggi jika dibandingkan dengan teman-temannya di dalam kelompok.

Menurut Hurlock (1980:223), selama masa remaja simbol status mempunyai empat fungsi yaitu: menunjukkan pada orang-orang lain bahwa remaja mempunyai status sosial ekonomi yang lebih tinggi daripada teman-teman lain dalam kelompok, remaja mencapai prestasi yang tinggi, remaja bergabung dengan kelompok dan merupakan anggota yang diterima kelompok karena penampilan atau perbuatan yang sama dan remaja memiliki status hampir dewasa di dalam masyarakat.

Salah satu minat remaja pada status pada simbol menurut Hurlock (1980: 223), ialah mempunyai status sosial ekonomi yang tinggi daripada teman-teman lain dalam kelompok. Menurut Sorokin (dalam Idianto, 2004: 48), status sosial adalah perbedaan penduduk atau masyarakat ke dalam kelas-kelas secara bertingkat, yang diwujudkan dalam kelas tinggi, kelas sedang dan kelas menengah. Kondisi ekonomi orang-tua sangat berpengaruh terhadap relasi pertemanan siswa. Menurut Maryati \&Suryawati (2004: 49), pembagian atau pelapisan masyarakat berdasarkan ekonomi akan membedakan masyarakat atas kepemilikan harta.

Berdasarkan hasil pengamatan di SMP Negeri 01 Argamakmur gejala yang diperoleh yaitu (1) siswa yang memiliki orang-tua dari golongan bawah merasa minder menjalin pertemanan karena, merasa berbeda dengan teman sebayanya yang memiliki fasilitas perlengkapan sekolah yang mewah (2) tidak bersedia tampil di depan orang banyak, karena merasa penampilannya berbeda dari teman sebayanya, (3) banyak siswa menjalin pertemanan dengan teman sebaya dilihat dari status penghasilan orang-tuanya. Hal ini diperkuat dengan adanya dengan perilaku mereka seperti, membuat kelompok teman sebaya yang beranggotakan siswa-siswi yang status social ekonomi orang-tuanya menengah dan atas, siswa yang status social ekonomi orang-tua menengah kebawah mengalami kesulitan dalam bergaul dengan teman 
sebayanya karena merasa rendah diri dengan siswa lainnya. Berdasarkan permasalahan yang telah diuraikan, peneliti merasakan perlu melakukan penelitian untuk membantu agar siswa-siswi dapat bersosialisasi dengan baik dan menjalin hubungan pertemanan dengan teman sebayanya.

Berdasarkan uraian di atas, maka perlu melakukan penelitian berjudul "Hubungan Antara Tingkat Penghasilan Orang-tua terhadap Relasi Pertemanan Siswa Kelas VIII”.

\section{Metode Penelitian}

Jenis penelitian ini adalah penelitian dengan pendekatan kuantitatif dengan rancangan penelitian korelasi. Menurut Sukardi (2003: 166), penelitian korelasi adalah suatu penelitian yang melibatkan tindakan pengumpulan data guna menentukan, apakah ada hubungan dan tingkat hubungan antara dua variabel atau lebih. Penelitian korelasional digunakan untuk mendeteksi sejauhmana variasivariasi pada suatu faktor berhubungan dengan variasi-variasi atau lebih faktor lain berdasarkan koefisien korelasinya.

Berdasarkan pendapat di atas, penelitian ini menjelasakan antara varabel (X) dan variabel (Y) yang merupakan variabel bebas $(\mathrm{X})$ yaitu tingkat penghasilan orang-tua dan variabel terikat (Y) yaitu relasi pertemanan siswa. Penelitian ini menjelaskan Hubungan antara Tingkat Penghasilan Orang-tua dengan Relasi Pertemanan Siswa SMP Negeri 01 Kelas VIII Argamakmur.

\section{Hasil dan Pembahasan}

Tabel 1.

\section{Crosstabulation}

\begin{tabular}{|c|c|c|c|c|c|c|}
\hline \multirow{2}{*}{$\begin{array}{c}\text { Kategori- } \\
\text { sasi }\end{array}$} & \multicolumn{5}{|c|}{ Relasi Pertemanan siswa } & \multirow{2}{*}{ Total } \\
\hline & ST & $\mathbf{T}$ & $\mathbf{S}$ & $\mathbf{R}$ & SR & \\
\hline Gol. Atas & $\begin{array}{c}3 \\
(7,9 \%)\end{array}$ & $\begin{array}{c}30 \\
(78,9 \\
\%)\end{array}$ & $\begin{array}{c}5 \\
(13,2)\end{array}$ & $\begin{array}{c}0 \\
(0 \%)\end{array}$ & $\begin{array}{c}0 \\
(0 \%)\end{array}$ & $\begin{array}{c}38 \\
(100 \% \\
)\end{array}$ \\
\hline $\begin{array}{c}\text { Gol. } \\
\text { Menengah }\end{array}$ & $\begin{array}{c}2 \\
(10,5 \\
\%)\end{array}$ & $\begin{array}{c}12 \\
(63,2 \\
\%)\end{array}$ & $\begin{array}{c}5 \\
(26,3 \\
\%)\end{array}$ & $\begin{array}{c}0 \\
(0 \%)\end{array}$ & $\begin{array}{c}0 \\
(0 \%)\end{array}$ & $\begin{array}{c}19 \\
(100 \% \\
)\end{array}$ \\
\hline $\begin{array}{c}\text { Gol. } \\
\text { Bawah }\end{array}$ & $\begin{array}{c}0 \\
(0 \%)\end{array}$ & $\begin{array}{c}6 \\
(31,6)\end{array}$ & $\begin{array}{c}11 \\
(57,9)\end{array}$ & $\begin{array}{c}1 \\
(5,3 \\
\%)\end{array}$ & $\begin{array}{c}1 \\
(5,3 \\
\%)\end{array}$ & $\begin{array}{c}19 \\
(100 \% \\
)\end{array}$ \\
\hline TOTAL & & & & & & 76 \\
\hline
\end{tabular}

Berdasarkan hasil penelitian yang telah dilakukan menunjukkan bahwa tingkat penghasilan orang-tua siswa kelas VIII SMP Negeri 01 Argamakmur tergolong tinggi. Menurut Idianto (2004: 51), ada beberapa faktor yang mempengaruhi tingkat sosial ekonomi seseorang antara lain: 1) kekayaan (capital), kekayaan adalah criteria ekonomi, oleh karena itu orang-orang yang berpenghasilan 
tinggi dikelompokkan ke dalam lapisan sosial yang tinggi pula, 2) Kekuasaan (power), Orang-orang yang memperoleh kesempatan menjadi pemimpin, baik melalui mekanisme pemilihan umum maupun secara turun-menurun (pada Negara system monarki), akan menempati kelas social lebih tinggi, 3) kehormatan atau kebangsawanan, golongan bangsawan baik pada masyarakat tradisional maupun pada masyarakat modern, selalu menduduki kelas sosial yang lebih tinggi. Mereka sangat dihormati, bahkan sering dijadikan sumber dalam memenuhi berbagai kebutuhan social manusia. Biasanya keturunan kelas bangsawan ini secara otomatis menjadi orang berada dan menyandang status sosial orang-tuanya, 4) Pendidikan, pada masyarakat yang mulai berkembang atau masyarakat praindustri, pendidikan menjadi suatu variabel yang amat penting, sehingga orang-orang yang memiliki pendidikan tinggi secara otomatis akan menempati lapisansosial yang tinggi pula.

Hasil penelitian diatas sejalan dengan teori yang diungkapkan Santrock (2007: 282), status sosial ekonomi adalah sebagai pengelompokkan orang berdasarkan kesamaan karakteristik pekerjaan, pendidikan dan ekonomi. Kemudian menurut Sorokin (dalam Idianto, 2004: 48), menyatakan bahwa sistem stratifikasi social adalah pembedaan penduduk atau masyarakat ke dalam kelas-kelas secara bertingkat, yang digolongkan dalam kelas tinggi, kelas sedang, dan kelas rendah.

Berdasarkan hasil penelitian yang telah dilakukan menunjukkan bahwa relasi pertemanan siswa kelas VIII SMP Negeri 01 Argamakmur tergolong tinggi. Menurut Hurlock (1980: 215) penggelompokan sosial yang dilakukan oleh teman sebaya sebagai berikut: Pengelompokan sosial yang sering terjadi pada masa remaja menurut Hurlock (1980: 215) sebagai berikut: 1) teman dekat remaja biasanya mempunyai dua atau tiga orang teman dekat atau sahabat karib. Mereka adalah sesama jenis kelamin yang mempunyai minat dan kemampuan yang sama, 2) kelompok kecil. Kelompok ini biasanya terdiri dari kelompok teman-teman dekat. Pada mulanya terdiri dari jenis kelamin yang sama-sama laki-laki atau sama-sama perempuan, tetapi kemudian berkembang meliputi kedua jenis, yaitu laki-laki dan perempuan, 3) kelompok besar. Kelompok besar yang terdiri dari beberapa kelompok kecil dan kelompok teman dekat, berkembang dengan meningkatnya minat terhadap pesta dan berkencan. Karena 
kelompok ini besar, maka penyesuaian minat berkurang di antara anggotaanggotanya, sehingga terdapat jarak sosial yang lebih besar di antara mereka, 4) kelompok yang teroganisir. Kelompok pemuda yang dibina oleh orang dewasa dibentuk oleh sekolah atau organisasi masyarakat untuk memenuhi kebutuhan sosial para remaja yang tidak mempunyai klik atau kelompok besar, 5) kelompok geng. Remaja yang tidak termasuk klik atau kelompok besar dan yang merasa tidak puas dengan kelompok yang terorganisasi, mungkin mengikuti kelompok geng. Anggota geng biasanya terdiri dari anakanak sejenis dan memiliki minat utama yang sama.

Hasil penelitian diatas sejalan dengan teori yang diungkapkan Santrock (2007: 55), kawan-kawan sebaya adalah anak-anak atau remaja yang memiliki usia atau tingkat kematangan yang kurang lebih sama. menerimanya dan kepada dirinya bergantung. Adapun dalam penelitianjuga menggunakan salah satu instrumen BK yaitu, sosiometri. Sosiometri ini digunakan untuk mendukung angket. Menurut Nurkancana (1990: 109), sosiometri adalah suatu metode mengumpulkan data tentang pola dan struktur hubungan antara individuindividu dalam suatu kelompok. Hasil penelitian ini menunjukan terdapat siswa yang disukai dalam bermain dan siswa yang tidak disukai dalam bermain. Penggunaan sosiometri ini untuk mengetahui hubungan pertemanan pada siswa kelas VIII di SMP Negeri 01 Argamakmur. Hasil dari sosiometri ini adalah hubungan pertemanan di dalam kelas yang diteliti sudah cukup baik, hanya ada seorang anak yang nomor absen nya 16 paling tidak disukai dari teman-teman yang lain sebanyak 9 orang siswa. Siswa yang tidak disukai oleh temantemannya ini adalah salah satu siswa yang memiliki orang-tua dari golongan menengah. Siswa tersebut belum dapat menjalin hubungan pertemanan yang baik, karena selalu menjahili temannya sehingga banyak dari teman-temannya yang tidak suka bermain dengannya.

Hasil penelitian yang telah dilakukan melalui pemberian berupa angket kepada 76 responden. Menurut Monk's dan Blair (dalam Arif, 2014: 15), faktor-faktor yang mempengaruhi interaksi teman sebaya memiliki 8 (delapan) aspek yaitu; 1) umur, 2) lingkungan, 3) kepribadian ekstrovet, 4) jenis kelamin, 5) besarnya kelompok, 6) keinginan untuk mempunyai status, 7) interaksi orang-tua, 8) pendidikan. Umur adalah salah satu faktor yang mempengaruhi interaksi teman sebaya. 
Hasil dari angket menunjukkan bahwa dalam memilih teman, siswa tidak melihat teman sebaya yang memiliki umur tua ataupun lebih muda. Faktor lain dari interasi teman sebaya yaitu lingkungan dan kepribadian ekstrovet. Lingkungan yang baik dapat membentuk perilaku yang baik juga. Bertingkah laku baik dan memiliki kepribadian yang baik dapat menjalin relasi pertemanan yang baik pula, tetapi dalam penelitian ini ada beberapa siswa yang masih tertutup dalam pertemananya. Siswa yang memiliki kepribadian tertutup lebih suka melakukan kegiatan seorang diri tanpa ditemani teman sebaya dan lebih banyak berdiam diri. Pada siswa yang berkepribadian terbuka memiliki kesamaan dengan teman sebayanya seperti, meniru penampilan dan meniru cara belajar. Siswa dikatakan berperilaku positif apabila meniru cara belajar teman sebaya, karena meniru cara belajar adalah salah satu cara agar siswa mendapatkan nilai yang bagus. Siswa perempuan cenderung lebih banyak berinteraksi dengan teman perempuannya. Jenis kelamin merupakan salah satu faktor yang mempengaruhi interaksi pertemanan..

Pengaruh kelompok terhadap sesama teman dari orang-orang sekitar menjadi besar bila besarnya kelompok. Mampu bekerjasama yang baik dengan teman sebaya dapat menjalin relasi pertemanan yang baik, dalam penelitian ini masih ada siswa yang tidak dapat bekerja sama dengan teman sebayanya misalnya, siswa tidak suka berbagi pendapat dengan teman sebaya, karena berbagi pendapat dengan teman sebaya hanya membuang-buang waktu saja. Ada beberapa siswa yang belum dapat beinteraksi dengan baik, siswa lebih suka bermain dengan teman kelas dan hanya memiliki teman dekat di dalam kelas. Selanjutnya faktor yang mempengaruhi interaksi teman sebaya yaitu interaksi orang-tua dan pendidikan. Suasana rumah yang tidak menyenangkan dan adanya tekanan dari orang-tua menjadi dorongan individu untuk berinteraksi dengan teman sebayanya.

Berdasarkan hasil penelitian yang telah dilakukan tersebut dapat disimpulkan bahwa terdapat hubungan antara tingkat penghasilan orang-tua dengan relasi pertemanan siswa kelas VIII di SMP Negeri 01 Argamakmur. Dengan demikian relasi pertemanan siswa kelas VIII di SMP Negeri 01 ini tergolong tinggi, karena banyak siswa yang memiliki orang-tua dari golongan atas.

\section{Kesimpulan}

Berdasarkan analisis data yang telah dilakukan dapat ditarik kesimpulan bahwa: 
1. Rata-rata tingkat penghasilan orang-tua siswa kelas VIII di SMP Negeri 01 Argamakmur tergolong tinggi.

2. Rata-rata tingkat relasi pertemanan siswa kelas VIII di SMP Negeri 01 Argamakmur tergolong tinggi.

3. Berdasarkan hasil analisis korelasi, hipotesis diterima. Dengan demikian terdapat hubungan positif yang signifikan antara tingkat penghasilan orang-tua dengan relasi pertemanan siswa kelas VIII di SMP Negeri 01 Argamakmur.

\section{Daftar Pustaka}

Arif, Muhammad M. (2014). "Hubungan Antara Interaksi Teman Sebaya dengan Kecerdasan Emosional Siswa Kelas V SD Negeri 1 Bedagas Kecamatan Pengadegan kabupaten Purbalingga". Skripsi. Fakultas Ilmu Pendidikan. Yogyakarta: Universitas Negeri Yogyakarta.

Azwar, S. (2012). Metode Penelitian. Yogyakarta: Pustaka Belajar.

Bagus, Arie Yusdianto. (2015). "Hubungan Penghasilan Orang-tua terhadap Motivasi Belajar Siswa dalam Pembelajaran Pendidikan Jasmani, Olahraga dan Kesehatan pada Siswa Kelas VII SMP Negeri 1 Wonoayu Sidoarjo". Jurnal Pendidikan Olahraga dan Kesehatan. Universitas Negeri Surabaya. Volume 03, Nomor 02.410 - 419.

Bangun, Muhammad dan Ari Wahyudi. (2016). "Pengaruh Status Ekonomi
Orang Tua terhadap Motivasi Belajar Siswa SMP Muhammadiyah 1 Jombang". Jurnal Pendidikan. Universitas Negeri Surabaya.Volume 04, Nomor 01. 206.

Caroline, dkk. (2015). "Hubungan Status Sosial Ekonomi Orang-tua dengan Motivasi Belajar pada Mahasiswa Angakatan 2013 Fakultas Kedokteran Universitas Sam Ratulangi”. Jurnal eBiomedik, Volume 3, Nomor 1. 303.

Dantes, Nyoman. (2012). Metode Penelitian. Yogyakarta: ANDI.

Ghozali, Imam. (2011). Aplikasi Analisis Multivariate dengan Program SPSS. Semarang: BP

Indri, Danti. (2016). "Pengaruh Pergaulan Kelompok Teman Sebaya dan Motivasi Belajar terhadap Prestasi Belajar Akuntansi Siwa Kelas XI Ips SMA Negeri 1 Parakan Tahun Ajaran 2015/2016". Skripsi. Fakultas Pendidikan Akuntansi. Yogyakarta: Universitas Negeri Yogyakarta.

Nurul, Fitri dan Sri Kustini. (2014). "Pengaruh Minat Belajar, Kondisi Sosial Ekonomi Orang-tua, dan Lingkungan Sekolah terhadap Prestasi Belajar Ekonomi pada Siswa Kelas XI IPS SMA N 4 Magelang Tahun Ajaran 2013/2014". Jurnal Pendidikan Ekonomi, Volume 3, Nomor 2. 249.

Rizki, Voni A. (2014). Studi Deskriptif Pada Siswa Akselerasi Kelas XI SMA Negeri 2 Kota Bengkulu. Skripsi. Fakultas Keguruan dan Ilmu Pendidikan. Bengkulu: Universitas Bengkulu. 
Rokhmatika, Lailatul dan Eko Darminto. (2013). "Hubungan Antara Persepsi Terhadap Dukungan Sosial Teman Sebaya Dan Konsep Diri Dengan Penyesuaian Diri di Sekolah Pada Siswa Kelas Unggulan".Jurnal Bimbingan Dan Konseling. Universitas Negeri Surabaya. Volume 01, Nomor 01. 147-157.

(2007). Perkembangan anak. Jakarta: Erlangga.

Silalahi. (2009). Metode Penelitian Sosial. Bandung: Refika Aditama

Waridah, Siti dkk. (2009). Sosiologi Untuk SMA Kelas 2. Jakarta: Bumi Aksara. 